\title{
Dar a mão: para além do gesto*1
}

\author{
Eliane Michelini Marraccini*2
}

Este trabalho baseia-se no atendimento psicanalitico de um paciente pelo breve período de três meses. Como emergiram instigantes questões ao longo do atendimento, mas em especial após o trágico desfecho, neste artigo é apresentado um esboço compreensivo e metapsicológico acerca de importantes e cruciais questões do desenvolvimento primitivo. As articulações teórico-clínicas constituem construtos e hipóteses a partir de uma relação analítica limitada no tempo, porém inspiradora de muitas reflexões e elaborações por parte do psicanalista.

Palavras-chave: Melancolia, neurose obsessiva, idealização, narcisismo, narcisismo destrutivo, ressentimento

${ }^{* 1}$ Este trabalho foi apresentado no VI Congresso Internacional de Psicopatologia Fundamental e XII Congresso Brasileiro de Psicopatologia Fundamental, de 4 a 7 de setembro de 2014, realizado em Belo Horizonte, MG, Br.

${ }^{* 2}$ Instituto Sedes Sapientiae (São Paulo, SP, Br.) 
Este trabalho baseia-se no atendimento clínico de um paciente pelo breve período de três meses. Assim, deve ser destacado que as articulações teórico-clínicas que apresentarei constituem construtos e hipóteses a partir desta relação analítica tão limitada. Porém, como emergiram instigantes questões, em especial após o trágico desfecho, considero interessante registrar o esboço compreensivo e metapsicológico que iniciei. Contaria com maiores e melhores elementos para fundamentá-lo caso este atendimento tivesse se estendido um pouco mais.

Pedro surpreendeu-me com uma pergunta inusitada ao telefone quando marcava a primeira consulta: "se eu dava a mão aos meus pacientes". Uma analista consultada anteriormente não o fazia, assim, queria saber de antemão, condição sine qua non na transferência que se anunciava. A espontaneidade da pergunta e o tom infantil com que a formulou chamaram minha atenção e provocaram um riso incontrolável. Quem seria ele, me perguntava.

No primeiro encontro, mostrou sua foto com bela mulher de corpo escultural, aparentando bem menos idade do que possuía. "Veja como é bonita, que corpo tem, esta é Dora". Esta imagem que o apresentava e convocava meu olhar em busca de reconhecimento, fez surgir indagações: Eram dois ou um? Seria ele um sujeito identificado com seu objeto amoroso ou reduzia-se a ser sombra daquela que resplandecia? Seria Dora um troféu, para este homem maduro e jogador premiado? Uma mulher-objeto, de quem lançava mão para um gozo secreto, ou estava completamente siderado pelo brilho daquela que o fascinava, constituindo-se em seu rendido objeto? Desde logo despontava a importância narcísica e o emaranhamento projetivo. Contrariamente ao enlevo de uma relação apaixonada, Pedro experimentava intensa angústia, era o que o trazia para a análise. 


\section{ARTIGO}

Ele vivia terrível conflito, sofrendo penosa e desgastante divisão afetiva que incorria em intensa culpa: a esposa e seus dois filhos de um lado, do outro a mulher que havia "virado sua cabeça" nos últimos três anos. Dora distinguia-se de suas aventuras anteriores e encontros a pagamento, pela atração sexual poderosa que emergiu nessa relação iniciada em uma casa de swing. Desde então, a vida de Pedro adquirira brilho especial e preenchera-se de sentido no oásis dessa companhia.

Ele tentara se separar da esposa retraída e fria, com quem estava casado havia mais de trinta anos, porém, sua pressão e chantagem, e em especial as ameaças do filho em romper relação, haviam feito Pedro retroceder. Impossível também se afastar e esquecer Dora, pois o contemplava com relações sexuais nunca experimentadas, prometendo viver só para ele, caso se separasse. Era o paraíso prometido do qual não conseguia desfrutar em paz! Pelo contrário, a atração e os ciúmes o torturavam, sentia-se possuído, obcecado, viciado nessa relação. Quando dela se afastava, atormentado pelo conflito e pela dúvida, Dora rapidamente buscava novos e variados parceiros sexuais, cuidando para que Pedro viesse a saber. Isto o corroía, tirava-lhe o sono e deixava-o vagar como um zumbi. Ele se tornava um resto, homem maduro impossibilitado de pilotar o timão de sua vida. Que enigma era este que a maturidade lhe reservara em formato de sereia? Um oásis antes do esmaecer das luzes? Ou seria o purgatório que finalmente o lançaria num abismo do qual não conseguiria emergir? Vida e morte lado a lado, Pedro sentia-se vítima de seus impulsos e desejos; ao mesmo tempo, consumia-se em conflito e culpa por comportá-los.

Seu pai fora profissional destacado, rígido e controlador junto à família. Pedro jamais conseguira trabalhar senão sob sua sombra, encolhido sob sua potente batuta. Mesmo após sua morte, Pedro conduzia os negócios deixados por ele, cultuando a imagem temida e idolatrada que parecia nunca ter conseguido enfrentar, superar. Sua passiva submissão ao homem forte de sua fantasia apontava para um Édipo não elaborado, condenando-o à vida de menino num cenário de homem.

Tinha ligação próxima com a mãe, sua confidente. Assim parecia retribuir a Pedro a acolhida nas dores e mazelas sofridas com o pai, homem que dava vazão a seus desejos sem reservas. Indicava não abrir mão do poder matriarcal e da revanche tardia transferida ao filho, determinando que Pedro priorizasse fidelidade à família acima de tudo. Imagens parentais tão fortes, impositivas e soberanas parecem ter levado Pedro a permanecer fixado ao infantil, para sempre refém do narcisismo dos pais. Repetia este cenário psíquico permeado de impossibilidades tornando-se refém de suas duas mulheres, seria isto? 
Para Dora, parecia representar um atraente joguete narcísico e, para a esposa, poderosa carta marcada, pois o condenava a viver um blefe como marido de estampa.

Pedro afirmava ter se deprimido com a perda do pai anos antes, e algo se anunciava como repetição provável em relação à Dora, hipotecado nesta relação narcísica de força inseparável. Ramificações desta teia infantil não superada pareciam também atá-lo emocionalmente aos filhos e esposa, pois deles era impossível destacar-se, ter vida própria, seguir seu desejo. Deveria seguir o modelo do pai, mantendo o casamento até o fim? Ou quem sabe tentar alcançar o ideal de filho virtuoso, colocando a família acima de si, segundo ditames maternos? Conferia eu que Pedro encontrava-se submerso e submetido, avançando rumo a um colapso. Vivia atravessado por angústia que o tornava impotente em suas ações e direções para a própria vida. Seu corpo já dava sinais deste limite e do empobrecimento dos processos de simbolização; a pressão se elevara, o sono estava perturbado por insônias renitentes.

No passado, tentara introduzir a esposa em espaços de sexo livre, mundo à parte onde exercia alguma liberdade clandestina. Porém, ela não descia aos porões do desejo, afastava-se assim do marido, que abria as comportas de suas fantasias buscando experiências sexuais cada vez mais excitantes. Ela lhe concedia o silêncio e o absolvia na complacência, desde que seu lugar de esposa não fosse abalado, triste personagem do "faz de conta" em que transformara sua vida.

Certa vez, Pedro trouxe para a sessão a foto de sua família junto à mãe, um quadro de Santa Ceia ao qual não parecia ele nem se integrar, nem verdadeiramente se destacar e emancipar, permanecendo sob a opressão da Tradição, Família e Propriedade. Acredito que Pedro necessitava me mostrar fotos das figuras reais de sua vida, pois emprestavam corpo para a apresentação projetiva dos objetos internos que se sobrepunham ao ego, submetendo-o e mantendo-o encarcerado em situação emocional que se figurava cada vez mais sem saída. Embora constituindo poderoso cinturão familiar que parecia sustentá-lo de algum modo, ele vergava sob o peso da culpa e se punia penitentemente por danos efetivos ou fantasiados. Além disto, derrapava na impossibilidade de reparação, pois parecia não confiar que pudesse levá-la a efeito junto a seus objetos amados, fosse Dora ou sua família.

A esposa o acompanhou para uma sessão certa vez. Pedro justificou pelo compromisso que teriam a seguir, resistindo à investigação dos imbricados significados que poderiam conter essa presença. Muitas vezes reconhecia a possibilidade e a necessidade de elucidar significados, mas o impasse subjetivo 


\section{ARTIGO}

o sufocava com a urgência de uma solução objetiva sobre o dilema que vivia e o consumia. Em tais momentos, menosprezava todo seu sofrimento, a divisão interna que o habitava, tornava-se um algoz para si mesmo e terminava rendido ao pathos. Não conseguia transformar o vivido em experiência e avançar, quase nem sobreviver ao impasse que sofria.

Em mais uma tentativa de separar-se da amante, Pedro voltara para a casa da família e dolorosamente mantinha-se sem vê-la. Certo dia, não resistira e telefonou-lhe sem nada dizer, "apenas para ouvir sua voz", embeber-se ao som daquela que não o deixava dormir, comer, trabalhar. De imediato, foi impiedosamente denunciado por Dora para a esposa. Isto provocou que se reforçassem a crucificação pela esposa e as ameaças do filho, caso não a abandonasse de vez. Pedro mergulhou na apatia, lançado no vazio da existência sem o brilho da amada. Enveredou mais intensamente na rota do afogamento melancólico, consumindo-se na dor da perda, massacrado por autorrecriminações e afogando-se em culpa.

Muitas vezes me colocava a questão analítica de como abrir espaço para ajudá-lo a ouvir, pensar, elaborar. Sua demanda reiterada pela indicação de uma solução urgente a ser consumida de imediato, ressaltava sua resistência e indicava a impossibilidade de um trabalho elaborativo mais profundo e consistente. Apresentava-se desta forma, na transferência, seu ego frágil afogado no vazio subjetivo, ansioso por se entregar ao outro para imprimir-lhe uma direção que, de modo passivo e infantil, procuraria seguir sem implicar-se nem responsabilizar-se. Repetição que viria a condenar o tratamento, pois ainda era deste modo que Pedro indicava viver sua relação com o outro. Uma alteridade incipiente, provável fruto da identificação projetiva de partes suas não integradas, mas funcionando de maneira soberana nos substratos de seu psiquismo.

Cerca de três meses após o inicio, Pedro decidiu interromper a análise, dizendo reconhecer a importância de um trabalho que pudesse compreender o sentido de seu sofrimento, mas não sentia que podia esperar, necessitava de ajuda mais direta, procuraria uma terapia comportamental, tinha urgência... Agradeceu a acolhida, elogiou o trabalho e saiu elegantemente.

Cerca de um ano depois, deparo com seu necrológio no jornal, e este impacto ressuscitou seu atendimento clínico, fazendo emergir inúmeras questões para reflexão e investigação. Muito em função disto, dei inicio a este trabalho que hoje apresento. Soube que Pedro morrera instantaneamente, em um acidente de moto. Assim se encerrara seu terrível sofrimento, com grande probabilidade, suponho, que terminou por abreviar seu fim. Creio 
que Eros, com sua força vital, não conseguiu deter o avanço de sua pulsão de morte, conduzindo-o do impasse ao colapso, e daí para esse trágico fim. $\mathrm{O}$ dilaceramento de sua fragilidade humana montada em potente cavalo sobre rodas foi imagem que para mim se apresentou, ao saber da forma em que sua morte se dera. Encerramento significativo para um homem que buscava domar as forças de Thanatos, tentando integrá-las e mitigá-las no interjogo com Eros, mas que não chegou a estruturar força egoica para lidar com sua realidade psíquica e enfrentar mais solidamente a relação com seus objetos internos e externos.

Este foi o fim trágico de Pedro, coroado por um necrológio em que se destacava a Organização fundada com o nome do pai, de quem era o júnior. Sombra que sempre o encobriu e parece ter coibido a constituição de uma identidade separada, mas que, no entanto, lhe servia de sustentação e, muito provavelmente, de importante troféu. Foi enterrado com essas honras de herança e pertencimento, talvez o único lugar que lhe foi destinado e que tenha conseguido ocupar ao longo da vida.

\section{Discussão}

Levanto aqui alguns pontos em torno deste caso clínico de breve atendimento, o qual, no meu entender, apontou para a importância de serem consideradas cruciais questões do desenvolvimento primitivo. Questões que suponho determinantes para o impasse subjetivo e falência psíquica de Pedro, tendo culminado no trágico fim deste paciente.

As fotos trazidas por Pedro foram alguns dos elementos que apresentou que indicavam a dependência de um olhar e necessidade de investimento do outro em sua direção. Winnicott (1975) considerou a troca com o outro materno a matriz identificatória do bebê, atraindo para si o olhar constitutivo da imagem de si mesmo. Balizamento interno de quem se é para si e para o outro, sentindo-se verdadeiro e importante, o que, em Pedro, parecia incipiente e vacilante. A analista consultada anteriormente que "não lhe dera a mão", parece tê-lo feito reviver esta falha constitutiva na edificação do narcisismo egoico, ainda muito dependente do apoio e sustentação por objetos externos. De algum modo, creio que também vivenciou, pelo menos em parte, este desamparo na relação analítica comigo, ainda não preparado para a representação simbólica de suas dores mais primitivas, necessitando de maior rêverie, fator da função alfa materna e inerente à função do analista, 


\section{ARTIGO}

como concebeu Bion (Zimerman, 2004). Se este atendimento clínico tivesse se estendido, talvez isto tivesse a chance de se estabelecer e possibilitar-lhe transformar o vivido, acessando angústias primitivas e alçando-as à possibilidade de representação. Quem sabe superando a intensa necessidade de ser amado e o sentimento de se sentir odiado e perseguido pelo superego, numa espécie de delírio de culpa ao qual o ego acabou por se entregar e morrer, como considerou Rosenfeld (1988) ao descrever a destrutividade ativa operante no narcisismo destrutivo.

A identificação projetiva maciça parecia promover defensivamente não apenas sua idealização do outro, fosse ele a mãe, o pai, Dora ou a própria família, como resultava na projeção do superego implacável naqueles objetos externos que sentia não apenas acusá-lo, mas que também o puniam com recriminações intoleráveis, produzindo culpas insaldáveis e penitências inesgotáveis. Conforme apontou Sarmento (2001), a renúncia pulsional não é suficiente para o superego, havendo a exigência de punição pelos desejos escondidos, numa reafirmação do seu poder junto ao ego.

Abraham, N. (1995) reconheceu a possibilidade de um sofrimento subjetivo advindo da excessiva marca da culpa nos primórdios da constituição egoica. Culpa pelo crime originário de deixar o estado de inocência original e despertar para o mundo, assumindo este desejo que, por sua vez, incorre em acusação interna. Culpa intrínseca à constituição da duplicidade sujeito-objeto e que resulta no mecanismo de incorporação onipotente, contrário à verdadeira introjeção que estruturaria e fortaleceria o ego, libertando-o da culpa excessiva. Pode-se supor que Pedro repetia o que vivenciara na relação com os objetos primários, o pai mais concretamente, porém irremediavelmente ligado à relação original com a mãe narcisista, que indicava não ter conseguido the destinar um lugar próprio, auxiliando Pedro desde a vida primitiva a consolidar identidade separada e destino autônomo.

Por outro lado, Stein (1988) destacou que todos os homens seriam alvo do ódio da mãe pela separação instaurada no nascimento. O próprio sujeito se odiando e carregando em si as Erínias de uma mãe, o que garantiria uma ligação indestrutível com a figura materna e uma perseguição vingativa com seu ódio. Este "cair do ódio materno sobre o filho" foi associado à descrição freudiana da melancolia e à depreciação de si, além de se aproximar sobremaneira da noção de melancolia em statu nascendi concebida por Klein (1940/1996b). Para esta, no processo constitutivo da distinção sujeito-objeto, a perda do objeto amado real ameaça com a possibilidade de perda do bom objeto interno, o que pode dificultar a consumação deste luto arcaico 
e representa sério risco para a sobrevivência do ego, que permaneceria alvo dos objetos maus internalizados. Na impossibilidade dessa superação crucial na estruturação primitiva, emergiriam no sujeito sérias dificuldades quando confrontado com perdas ao longo da vida. Pedro indicava contar com falhas constitutivas que não conseguiam garantir uma separação do objeto amado real sem correr o risco de sucumbir à catástrofe egoica e à hemorragia do eu. Sugeria não ter levado a efeito o primitivo "trabalho da melancolia" que Rosenberg (2003) descreveu como essencial para promover o destacamento das representações do sujeito e objeto. Pois, quando estas permanecem coladas, se daria a predisposição à melancolia, o sujeito reagindo à raiva do objeto com um novo investimento narcisista, dando-se pela regressão à identificação narcisista e fixação ainda mais estreita ao objeto. Além disto, o sujeito utilizaria a raiva para destruir a si mesmo, ao invés de vivenciar a culpa pelas fantasias de ataque ao objeto. Acredito ser esta condição plausível e significativa na compreensão do que ocorria com Pedro.

É interessante a articulação que promoveu Kancyper (1994) entre ressentimento e remorso. Destacou que o ressentimento em relação ao objeto pode impedir a efetiva separação e mudança do investimento em direção a outros objetos, dificultando a elaboração do luto. Apesar da aparente inércia psíquica, podem ter lugar múltiplas batalhas de ambivalência a fim de perpetuar a viscosidade da libido ao objeto do qual o sujeito não consegue se separar; isto o mantém preso a um passado com contas que não foram saldadas. Esse autor destacou como Freud, que a viscosidade da libido e a rigidez do narcisismo podem ser responsáveis por limites à ação terapêutica. Por outro lado, apontou que o remorso advém de uma culpa irreparável que, pelo menos em parte, permanece desconhecida para o sujeito, instituindo uma dívida insaldável. Ocorrendo sempre novas retaliações, pois o superego atua em função de autopunição e tortura do próprio sujeito. O remorso funcionaria como uma representação obsessiva e dolorosa da tentativa frustrada em elaborar a culpa inconsciente e, ao mesmo tempo, o castigo imposto atenderia à necessidade de um sofrimento masoquista. Suspeito que Pedro padecesse não apenas de ressentimento como de remorso, condições não excludentes e, por vezes, difíceis de serem absolutamente distintas na clínica, como apontou Kancyper (1994).

Em outro vértice, Abraham, K. (1924/1970) destacou aproximações entre a neurose obsessiva e a melancolia, relacionando-as a dois estágios da fase sádico-anal da libido. Com alto grau de ambivalência, comportariam tendências de destruir e ao mesmo tempo de conservar o objeto, havendo falta de ajustamento entre as emoções de amor e ódio, e entre as tendências 
homossexuais e heterossexuais. Como salientou Peres (1996), na neurose obsessiva o ego não aceita a culpa, enquanto na melancolia admite a culpa e aceita o castigo. No caso de Pedro, o conflito ambivalente não conseguiu avançar e dar lugar a uma integração de afetos e articulação com a realidade, o que parece ter produzido uma regressão assustadora que culminou na atuação de impulsos destrutivos contra si. De acordo com o que sugeriu Rosenfeld (1988) sobre a culpa do melancólico, as atuações de Pedro em busca de excitantes experiências sexuais poderiam indicar uma busca de Eros "do lado de fora", constituindo uma defesa contra seus impasses mais profundos e a pulsão de morte indomável internamente.

Retomando a ideia de Abraham e Glover sobre ser o suicídio um ataque contra o objeto introjetado, acrescentou Klein (1935/1996a) que ao desejar assassinar os objetos maus e exterminar o próprio id que é odiado, o sujeito procuraria, ao mesmo tempo, salvar seus objetos amados internos ou externos e a parte do ego identificada com estes. Além disto, pontuou que o ódio e a vingança contra os objetos reais podem desempenhar papel importante no ato destrutivo contra si, dada a ausência de uma introjeção sólida do bom objeto que conseguisse garantir a sustentação egoica necessária para suportar os impulsos destrutivos em relação aos objetos que também são amados. Este parecia ser o doloroso cenário interno em que Pedro não encontrava saída integradora possível, pois na ilusão de salvar a todos a quem amava de seus impulsos destrutivos pode ter revertido o ódio em direção a si e atuado o seu próprio fim.

Ao final, encerro minhas considerações afirmando que todo este trabalho que dei início em torno deste caso clínico tem demonstrado, cada vez mais, que a escuta psicanalítica não se encerra com a morte e a elaboração do analista; persiste com o que permanece vivo dentro dele, do paciente que se foi e da relação que se deu.

\section{Referências}

Abraham, K. (1970). Breve estudo do desenvolvimento da libido, visto à luz das perturbações mentais. In K. Abraham, Teoria psicanalítica da libido - sobre o caráter e o desenvolvimento da libido (pp. 81-160). Rio de Janeiro: Imago. (Trabalho original publicado em 1924).

Abraham, N. (1995). O “crime" da introjeção. In N. Abraham, M. Torok, A casca e o núcleo (pp. 119-126). São Paulo: Escuta. 
Kancyper, L. (1994). Ressentimento e remorso: estudo psicanalítico. São Paulo: Casa do Psicólogo.

Klein, M. (1996a). Uma contribuição à psicogênese dos estados maníaco-depressivos. In Amor, culpa e reparação e outros trabalhos (1921-1945) (pp. 301-329). Rio de Janeiro: Imago. (Trabalho original publicado em 1935).

Klein, M. (1996b). O luto e suas relações com os estados maníaco-depressivos. In Amor, culpa e reparação e outros trabalhos (1921-1945) (pp. 385-412). Rio de Janeiro: Imago. (Trabalho original publicado em 1940).

Peres, U. T. (1996). Dúvida melancólica, dívida melancólica, vida melancólica. In U. T. Peres (Org.), Melancolia (pp. 11-71). São Paulo: Escuta.

Rosenberg, B. (2003). Masoquismo mortífero e masoquismo guardião da vida. São Paulo: Escuta.

Rosenfeld, H. (1968). Da psicopatologia do narcisismo: uma aproximação clínica. In Os estados psicóticos (pp. 193-204). Rio de Janeiro: Zahar.

Rosenfeld, H. (1988). Narcisismo destrutivo e pulsão de morte. In Impasse e interpretação (pp. 139-166). Rio de Janeiro: Imago.

Sarmento, R. (2001). Nós não somos sem ela. In U. T. Peres (Org.), Culpa (pp. 213-219). São Paulo: Escuta.

Stein, C. (1988). As erínias de uma mãe - ensaio sobre o ódio. São Paulo: Escuta.

Winnicott, D. W. (1975). O brincar e a realidade. Rio de Janeiro: Imago.

Zimerman, D. E. (2004). Bion: da teoria à prática - uma leitura didática. Porto Alegre: Artmed.

\section{Resumos}

(Providing help: going beyond gestures)

This study is based on the psychoanalytical care of a patient for a brief threemonth period. Since thought-provoking questions emerged during this period of care, and especially after its tragic outcome, this paper presents a comprehensive and meta -psychological outline concerning important and crucial early human development issues. The theoretical and clinical connections represent constructs and hypotheses that are based on an analytical relationship that is limited in time, but that has inspired many reflections and formulations by psychoanalysts.

Key words: Melancholy, obsessional neurosis, idealization, narcissism, destructive narcissism, resentment 


\section{ARTIGO}

(Tendre la main: bien plus qu'un geste)

Ce travail s'intéresse à la prise en charge psychanalytique d'un patient pendant une brève période de trois mois. Du fait de l'émergence de questions suscitant la réflexion au cours de la prise en charge, mais surtout après l'issue tragique, on présentera dans cet article un aperçu global et métapsychologique des questions importantes et cruciales liées au développement précoce. Les articulations théoriques et cliniques constituent des constructions et des hypothèses basées sur une relation analytique limitée dans le temps, mais donnant néanmoins lieu à maintes réflexions et élaborations de la part du psychanalyste.

Mots clés: Mélancolie, névrose obsessionnelle, idéalisation, narcissisme, narcissisme destructeur, ressentiment

(Dar la mano: más allá del gesto)

Este trabajo se basa en la atención psicoanalítica de un paciente durante un breve periodo de tres meses. Como surgieron preguntas intrigantes a lo largo de la atención, especialmente después del trágico desenlace, en este artículo se presenta un esbozo comprensivo y metapsicológico sobre importantes y cruciales preguntas relacionadas al desarrollo primitivo. Las articulaciones teórico-clínicas componen constructos e hipótesis a partir de una relación analítica limitada en el tiempo, que aun así inspira muchas reflexiones y elaboraciones por parte del psicoanalista.

Palabras clave: Melancolía, neurosis obsesiva, idealización, narcisismo, narcisismo destructivo, resentimiento

(Die Hand halten: jenseits der Geste)

Die vorliegende Arbeit basiert auf der psychoanalytischen Betreuung eines Patienten während einer kurzen Frist von drei Monaten. Da jedoch während der Behandlung anregende Fragen auftraten, insbesondere aufgrund des tragischen Ergebnisses dieser Betreunng, bietet der vorliegende Artikel eine umfassende und metapsychologische Darstellung der wichtigen und entscheidenden Fragen der primitiven Entwicklung. Die theoretisch-klinischen Artikulierungen münden in Konstrukte und Hypothesen, die das Produkt dieser zeitlimitierten analytischen Beziehung sind. Diese stellt sich jedoch für den Psychoanalytiker als inspirierende Quelle weiterer Überlegungen und Betrachtungen heraus.

Schlüsselwörter: Melancholie, zwanghafte Neurose, Idealisierung, Narzissmus, zerstörerischer Narzissmus, Missgunst.

（伸出援助之手：超越手势之外）

本论文根据对患者进行三个月的短期精神分析治疗。在治疗过程中出现了 一些非常有意义的问题, 特别是在发生悲剧之后。本论文提出了一个关于病情 早期发展的关键问题的全面性, 宏观心理学概述。本文在分析和假设基础上对 
一个病例提出一些理论一临床方面结论, 希冀这些结论对精神分析学家有所启 发。

关键字：忧郁、强迫症、理想化、自恋、破坏性自恋、怨恨症

Citação/Citation: Marraccini, E.M. (2016, junho). Dar a mão: para além do gesto. Revista Latinoamericana de Psicopatologia Fundamental, 19(2), 275-286.

Editores do artigo/Editors: Prof. Dr. Manoel Tosta Berlinck e Profa. Dra. Sonia Leite

Recebido/Received: 16.8.2015/ 8.16.2015 Aceito/Accepted: 21.9.2015 / 9.21.2015

Copyright: (C) 2009 Associação Universitária de Pesquisa em Psicopatologia Fundamental/ University Association for Research in Fundamental Psychopathology. Este é um artigo de livre acesso, que permite uso irrestrito, distribuição e reprodução em qualquer meio, desde que o autor e a fonte sejam citados / This is an open-access article, which permits unrestricted use, distribution, and reproduction in any medium, provided the original authors and sources are credited.

Financiamento/Funding: A autora declara não ter sido financiada ou apoiada/ The author has no support or funding to report.

Conflito de interesses/Conflict of interest: A autora declara que não há conflito de interesses / The author has no conflict of interest to declare.

\section{Eliane Michelini Marraccini}

Psicóloga; Psicanalista; Mestre e Doutora pelo Programa de Estudos Pós-Graduados em Psicologia Clínica da Pontifícia Universidade Católica de São Paulo - PUC-SP (São Paulo, SP, Br); Professora e Supervisora do Curso de Especialização "Formação em Psicanálise" do Instituto Sedes Sapientiae (São Paulo, SP, $\mathrm{Br})$; Autora de Encontro de mulheres - uma experiência criativa no meio da vida (Casa do Psicólogo, 2001); Organizadora da coletânea $O$ eu em ruína: perda e falência psíquica (Primavera Editorial, 2010); Coorganizadora da coletânea Limites de Eros (Primavera Editorial, 2012) além de diversos artigos e capítulos de livros.

R. Pará, 50/44

01243-020 São Paulo, SP, Br

eliane.marraccini@gmail.com 